\title{
Correlation between percutaneous transthoracic needle biopsy and recurrence in stage I lung cancer: a systematic review and meta-analysis
}

\author{
Haichao Li, Rong Chen and Jian Zhao* (1)
}

\begin{abstract}
Background: To systematically evaluate the correlation between percutaneous transthoracic needle biopsy (PTNB) and recurrence in stage I lung cancer.

Methods: The databases of PubMed, EMbase, The Cochrane Library, CNKI, WanFang Data and China Biology Medicine disc were retrieved to collect relevant literatures about the correlation between PTNB and recurrence in stage I lung cancer. The retrieval time was limited from the time of their database establishment to April 30/ 2020.Screened the literature, extracted the data and assessed the quality of studies included. Then the meta-analysis was performed by using Stata 16.0 software.

Results: A total of 8 cohort studies involving 2760 lung cancer patients were included. The results of meta-analysis showed that PTNB did not increase the risk of total recurrence and pleural recurrence in the patients with stage I lung cancer. The result of subgroup analysis is according to the tumor location. For stage I lung cancer, PTNB will increase the risk of pleural recurrence in patients with sub-pleural lesions but not in those without sub-pleural lesions.

Conclusions: To stage I lung cancer, PTNB is not associated with the total recurrence and pleural recurrence but PTNB will increase the risk of pleural recurrence in patients with sub-pleural lesions.
\end{abstract}

Keywords: Percutaneous transthoracic needle biopsy, Stage I lung cancer, Recurrence, Meta-analysis

Lung cancer is one of the malignant tumors with the highest morbidity and mortality in the world. In recent years, with the application of low-dose CT in screening for lung cancer, the rate of discovering lung mass has gradually increased. However, it is difficult to make qualitative diagnosis of lung occupying by imaging alone. Percutaneous transthoracic needle biopsy (PTNB) is more and more commonly used in the diagnosis of lung occupying lesions. But the operation's safety of metastasis along the needle tract has not yet been determined. Some studies have

\footnotetext{
* Correspondence: zhaojianjn@sdu.edu.cn

Department of Thoracic Surgery, Qilu Hospital, Cheeloo College of Medicine, Shandong University, Jinan 250012, Shandong, China
}

shown that this operation will have the risk of breast wall implant metastasis [1], pleural metastasis [2, 3] and so on, while other studies showed that this operation is safe in the diagnosis $[4,5]$, and tumor metastasis along the needle track is relatively rare [6]. The purpose of this metaanalysis is to evaluate the risk of recurrence in patients with lung cancer caused by PTNB and to provide evidence-based medicine in clinical diagnosis.

\section{Materials and methods \\ Literature inclusion and exclusion \\ Study type \\ Randomized controlled study and cohort study}

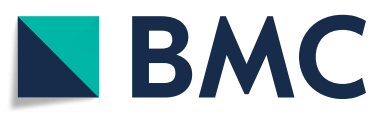

(c) The Author(s). 2020 Open Access This article is licensed under a Creative Commons Attribution 4.0 International License, which permits use, sharing, adaptation, distribution and reproduction in any medium or format, as long as you give appropriate credit to the original author(s) and the source, provide a link to the Creative Commons licence, and indicate if changes were made. The images or other third party material in this article are included in the article's Creative Commons licence, unless indicated otherwise in a credit line to the material. If material is not included in the article's Creative Commons licence and your intended use is not permitted by statutory regulation or exceeds the permitted use, you will need to obtain permission directly from the copyright holder. To view a copy of this licence, visit http://creativecommons.org/licenses/by/4.0/ The Creative Commons Public Domain Dedication waiver (http://creativecommons.org/publicdomain/zero/1.0/) applies to the data made available in this article, unless otherwise stated in a credit line to the data. 


\section{Study subjects}

Patients with stage I lung cancer

\section{Intervention measures}

Various types of PTNB, such as CT guided PTNB or ultrasound guided PTNB. Studies focusing on transbronchial or intraoperative needle biopsy will be excluded.

\section{Exclusion criteria}

(1) No PTNB study was conducted; (2) letters, repeated publications, animal experiments, case reports, literature reviews, conference posters, conference abstracts and seminars; (3) four grid table values could not be obtained; (4) articles not published in English or Chinese and studies published in national journals of nonEnglish speaking countries.

\section{Search strategies}

Databases: PubMed, EMBASE, the Cochrane Library, CNKI, CBM and Wanfang database. Key words: "lung neoplasm", "biopsy, needle", "recurrence", "randomized controlled trials" or "prospective studies" or "retrospective study". The retrieval period is from the establishment of the database to 2020.04.30. The combination of subject words and free words is adopted in the retrieval, and there is no limit to the languages. At the same time, the references included in the research are supplemented by secondary retrieval. Taking PubMed as an example, the retrieval strategy is as follows:

\#1 $\quad((((()((()((()((“$ Lung Neoplasms”[Mesh]) OR Lung Neoplasms [Title/Abstract]) OR Pulmonary Neoplasms [Title/Abstract]) OR Neoplasms, Lung [Title/Abstract]) OR Lung Neoplasm [Title/ Abstract]) OR Neoplasm, Lung [Title/Abstract]) OR Neoplasms, Pulmonary [Title/Abstract]) OR Neoplasm, Pulmonary [Title/Abstract]) OR Pulmonary Neoplasm [Title/Abstract]) OR Lung Cancer [Title/Abstract]) OR Cancer, Lung [Title/ Abstract]) OR Cancers, Lung [Title/Abstract]) OR Lung Cancers [Title/Abstract]) OR Pulmonary Cancer [Title/Abstract]) OR Cancer, Pulmonary [Title/Abstract]) OR Cancers, Pulmonary [Title/ Abstract]) OR Pulmonary Cancers [Title/Abstract]) OR Cancer of the Lung [Title/Abstract]) OR Cancer of Lung [Title/Abstract]

\#2 Needle [Title/Abstract]) OR Biopsies, Needle [Title/ Abstract]) OR Needle Biopsies [Title/Abstract]) OR Needle Biopsy [Title/Abstract]) OR Aspiration Biopsy [Title/Abstract]) OR Aspiration Biopsies [Title/Abstract]) OR Biopsies, Aspiration [Title/ Abstract]) OR Biopsy, Aspiration [Title/Abstract]) OR Puncture Biopsy [Title/Abstract]) OR Biopsies,
Puncture [Title/Abstract]) OR Biopsy, Puncture [Title/Abstract]) OR Puncture Biopsies [Title/ Abstract]

\#3 ((((((“Recurrence”[Mesh]) OR Recurrence [Title/ Abstract]) OR Recurrences [Title/Abstract]) OR Recrudescence [Title/Abstract]) OR Recrudescences [Title/Abstract]) OR Relapse [Title/Abstract]) OR Relapses [Title/Abstract]

\#4. $(((((((($ “Prospective Studies”[Mesh]) OR Prospective Studies [Title/Abstract]) OR Prospective Study [Title/Abstract]) OR Studies, Prospective [Title/ Abstract]) OR Study, Prospective [Title/Abstract]) OR Prospective [Title/Abstract]) OR Prospectively [Title/Abstract] $))$ OR $(((((($ ("Retrospective Studies"[Mesh]) OR Retrospective Studies [Title/ Abstract]) OR Studies, Retrospective [Title/ Abstract]) OR Study, Retrospective [Title/Abstract]) OR Retrospective Study [Title/Abstract]) OR Retrospective [Title/Abstract]) OR Retrospectively [Title/Abstract])) OR ((((“"Randomized Controlled Trial" [Publication Type]) OR Randomized Controlled Trial [Title/Abstract]) OR Randomized [Title/Abstract]) OR Randomizedly [Title/Abstract]) OR Placebo [Title/Abstract])

\#5 \#1 AND \#2 AND \#3 AND \#4

\section{Literature screenings and data extraction}

The data included first author, publication time, sample characteristics (number, size, stage, metastasis, pleural recurrence, etc.) and so on. If there is a lack of relevant data in the literatures, contact the relevant authors, and if the relevant data cannot be obtained, they will be excluded.

\section{Quality evaluation}

For randomized controlled trials, methodological quality was assessed using the five point Jadad scale. The bias risk of cohort studies were evaluated according to the Newcastle-Ottawa scale (NOS) and the results were cross-checked.

\section{Statistical analyses}

We used Stata16.0 software for statistical analyses and the degree of heterogeneity was determined by the size of $\mathrm{I}^{2}$ value. $\mathrm{I}^{2}>50 \%$ indicates obvious heterogeneity, we choose random effect model to merge statistics. $\mathrm{I}^{2}<50 \%$ represents that there is small heterogeneity, we select the fixed effect model to merge statistics. For the comparison of the total recurrence rate and pleural metastasis rate of lung cancer between PTNB group and NPTNB group, the relative risk (RR) was used to represent the effect. The interval was estimated by $95 \%$ confidence interval (CI) and $p<0.05$ means the difference was statistically significant. 


\section{Results}

\section{Literature screen}

We obtain 428 relative literatures, including 58 Chinese literatures and 370 English literatures. After reading the title and abstract, we excluded the literature that did not meet the inclusion criteria and included 10 articles. After reading the full text, we finally included 8 articles $[2,3$, $7-12$ ], with a total of 2760 patients having lung cancers. The literature screening process is shown in Fig. 1:

\section{Methodological quality evaluations of included studies}

All included studies were cohort studies, assessed by the Newcastle-Ottawa 9-star scale (NOS). The NOS scale is an 8-point scoring tool used to evaluate the selection of study population, study comparability, follow-up results and study results. The score is used to evaluate the quality of literature research, with totaling 8 points. The evaluation results are shown in Table 1.

\section{Basic characteristics of included studies}

A total of 8 cohort studies were included. The basic characteristics of the included studies are shown in Table 2.
The total recurrence of lung cancer includes local recurrence and distant metastasis. Local recurrence is defined as any recurrence in the ipsilateral chest cavity including ipsilateral pleural recurrence. Distant metastasis refers to pleural, contralateral lung, extra-thoracic metastasis or recurrence of pericardial effusion. Pleural recurrence refers to the new development of new pleural nodules or pleural effusions detected by the chest CT scan. Pleural biopsy or pleural fluid cytology can confirm pleural recurrence.

\section{The effect of PTNB on patients' total recurrence rate}

Seven studies compared the total recurrence rate between the PTNB group and the non-PTNB group (Table 3). Significant heterogeneity was found in the study $\left(\mathrm{I}^{2}=59.9 \%, p=0.021\right.$; Fig. 2$)$, so a random effect model was applied. The total relative risk ratio (RR) was 1.055 (95\% CI, 0.799-1.392; $p=0.705$; Fig. 2), indicating that there was no significant correlation between PTNB and the total recurrence rate of stage I lung cancers.

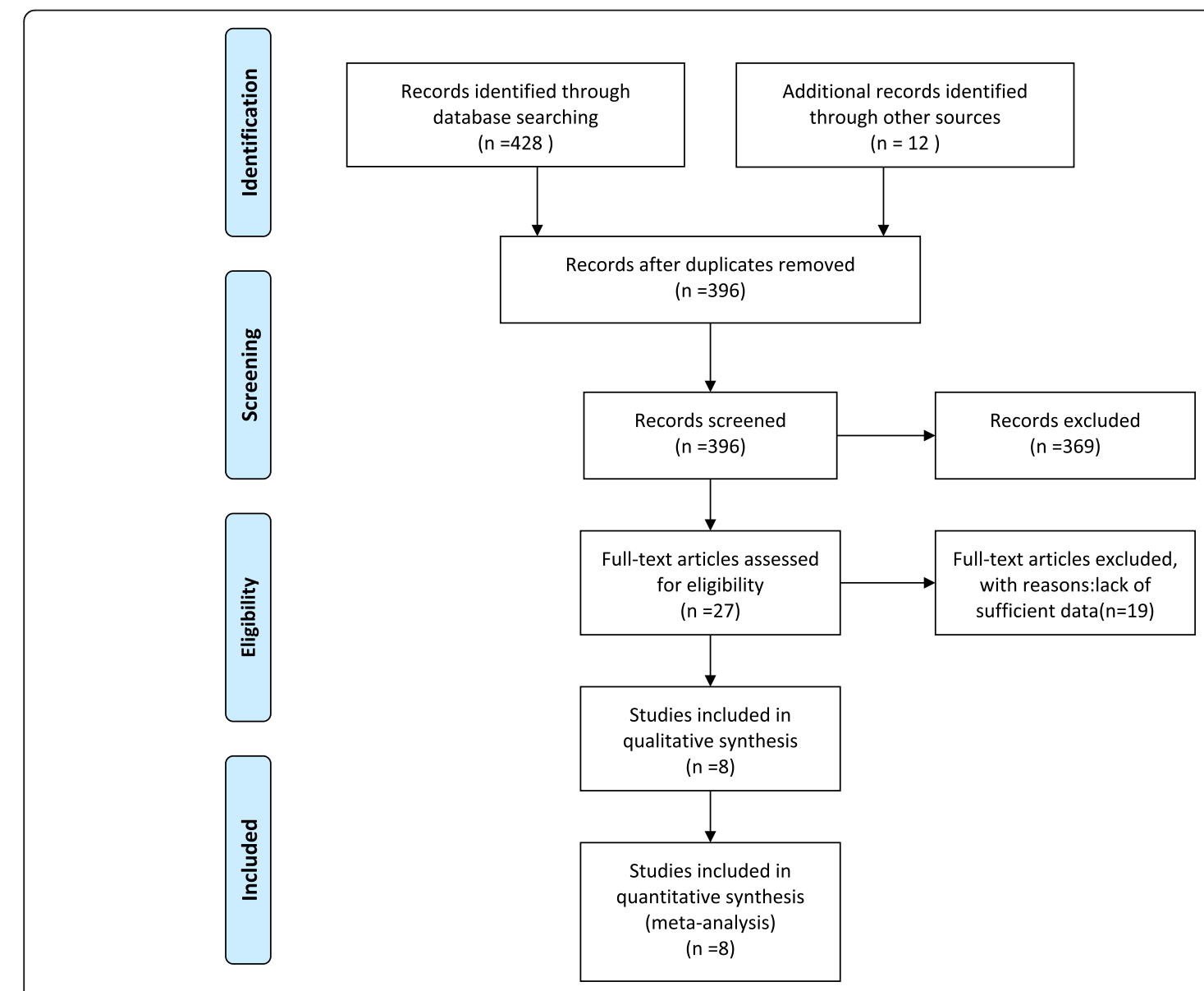

Fig. 1 The literature screening process 
Table 1 Methodological quality evaluation of included studies

\begin{tabular}{|c|c|c|c|c|c|c|c|c|c|}
\hline \multirow[t]{2}{*}{ Inclusion study } & \multicolumn{4}{|l|}{ Selection } & \multirow[t]{2}{*}{ comparabbility } & \multicolumn{3}{|l|}{ Exposure } & \multirow[t]{2}{*}{ tota } \\
\hline & $\begin{array}{l}\text { adequate case } \\
\text { definition }\end{array}$ & $\begin{array}{l}\text { case } \\
\text { representativeness }\end{array}$ & $\begin{array}{l}\text { control } \\
\text { selection }\end{array}$ & $\begin{array}{l}\text { control } \\
\text { definition }\end{array}$ & & $\begin{array}{l}\text { ascertainment } \\
\text { of exposure }\end{array}$ & $\begin{array}{l}\text { same } \\
\text { method }\end{array}$ & non-response rate & \\
\hline $\begin{array}{l}\text { Matsuguma, H. } \\
2005[3]\end{array}$ & 1 & 1 & 1 & 1 & 1 & 1 & 1 & 1 & 8 \\
\hline Inoue, M. 2011 [2] & 1 & 1 & 1 & 1 & 1 & 1 & 1 & 1 & 8 \\
\hline Asakura, K. 2012 [11] & 1 & 1 & 1 & 1 & 1 & 1 & 1 & 1 & 8 \\
\hline $\begin{array}{l}\text { Flechsig. P. } 2015 \\
\text { [10] }\end{array}$ & 1 & 1 & 1 & 1 & 0 & 1 & 1 & 1 & 7 \\
\hline $\begin{array}{l}\text { Kashiwabara, K. } \\
2016 \text { [12] }\end{array}$ & 1 & 1 & 1 & 1 & 1 & 1 & 1 & 1 & 8 \\
\hline Moon, S.M. 2017 [7] & 1 & 1 & 1 & 1 & 1 & 1 & 1 & 1 & 8 \\
\hline $\mathrm{Hu}$, C. 2018 [9] & 1 & 1 & 1 & 1 & 0 & 1 & 1 & 1 & 7 \\
\hline Ahn, S. Y. 2019 [8] & 1 & 1 & 1 & 1 & 1 & 1 & 1 & 1 & 8 \\
\hline
\end{tabular}

The effect of PTNB on patients' pleural recurrence rate Seven studies compared the pleural recurrence rate between the PTNB group and the non-PTNB group (Table 4). Significant heterogeneity was found in the study $\left(\mathrm{I}^{2}=62.1 \%, p=0.015\right.$; Fig. 3$)$, so using a random effect model. The total relative risk ratio (RR) was 2.098 (95\% CI, 0.985-4.469; $p=0.055$; Fig. 3), indicating that PTNB had no significant correlation with the pleural recurrence rate of stage I lung cancers.

\section{The effect of PTNB on the recurrence of pleura in patients with sub-pleural lesions}

Our study was analyzed by subgroup according to the tumor site. Three studies compared with pleural recurrence rates between PTNB and non-PTNB groups of patients with sub-pleural lesions (Table 5). A small heterogeneity was found in the study $\left(\mathrm{I}^{2}=2.3 \%, p=0.359\right.$; Fig. 4), and a fixed effect model was used. For patients with sub-pleural lesions, the total relative risk ratio (RR) was 4.891 (95\% confidence interval, 2.012-11.891; $p=$ 0.000 ; Fig. 4). The results indicate that for stage I lung cancers, PTNB will increase the pleural recurrence rate in patients with sub-pleural lesions.

The effect of PTNB on pleural recurrence in patients without sub-pleural lung cancer

Three studies compared the pleural recurrence rate between PTNB and non-PTNB groups for patients without sub-pleural lung cancer (Table 6). Significant heterogeneity was found in the study (I2 $=51.3 \%, p=0.128$; Fig. 5),

Table 2 Basic characteristics of included studies

\begin{tabular}{|c|c|c|c|c|c|c|c|c|c|c|c|c|}
\hline \multirow[t]{2}{*}{ Study object } & \multirow[t]{2}{*}{ Study type } & \multirow[t]{2}{*}{ Location } & \multicolumn{2}{|c|}{ Sample size } & \multirow[t]{2}{*}{ Period } & \multicolumn{2}{|c|}{$\begin{array}{l}\text { Median } \\
\text { follow-up } \\
\text { (months) }\end{array}$} & \multirow[t]{2}{*}{ Stage } & \multicolumn{2}{|c|}{ tumor size (mm) } & \multirow[t]{2}{*}{$\begin{array}{l}\text { Needle } \\
\text { size }\end{array}$} & \multirow[t]{2}{*}{ therapy } \\
\hline & & & PTNB & NPTNB & & PTNB & NPTNB & & PTNB & NPTNB & & \\
\hline $\begin{array}{l}\text { Matsuguma, H. } \\
2005 \text { [3] }\end{array}$ & Cohort stud & Japan & 66 & 224 & $\begin{array}{l}1986,10- \\
2000.12\end{array}$ & 80 & 80 & I & 23.8 & $29.0 / 39.5$ & $\begin{array}{l}18 \\
\text { gauge }\end{array}$ & Surgery \\
\hline Inoue, M. 2011 [2] & Cohort stud & Japan & 131 & 316 & 1992-2008 & 66.5 & 57.9 & 1 & 25 & 27 & $\begin{array}{l}18 \\
\text { gauge }\end{array}$ & Surgery \\
\hline $\begin{array}{l}\text { Asakura, K. } 2012 \\
\text { [11] }\end{array}$ & Cohort stud & Japan & 124 & 197 & $\begin{array}{l}2002.10- \\
2009.02\end{array}$ & 45 & 42 & I & $19 \pm 9$ & $25 \pm 9$ & $\begin{array}{l}18 \\
\text { gauge }\end{array}$ & Surgery \\
\hline $\begin{array}{l}\text { Flechsig. P. } 2015 \\
\text { [10] }\end{array}$ & Cohort stud & Germany & 26 & 9 & 2003-2010 & 17 & 17 & I & $\mathrm{Nr}^{*}$ & $\mathrm{nr}$ & $\begin{array}{l}15 \\
\text { gauge }\end{array}$ & $\begin{array}{l}\text { Surgery } \\
\text { chemotherapy, } \\
\text { radiotherapy }\end{array}$ \\
\hline $\begin{array}{l}\text { Kashiwabara, K. } \\
2016 \text { [12] }\end{array}$ & Cohort stud & Japan & 63 & 86 & $\begin{array}{l}2009.04- \\
2014.03\end{array}$ & 43.2 & 43.2 & I & 21 & 27 & $\begin{array}{l}21 \\
\text { gauge }\end{array}$ & Surgery \\
\hline Moon, S.M. 2017 [7] & Cohort stud & Korea & 243 & 149 & $\begin{array}{l}2009.01- \\
2010.12\end{array}$ & 54 & 51 & I & not sure & not sure & $\begin{array}{l}18 / 20 \\
\text { gauge }\end{array}$ & Surgery \\
\hline $\mathrm{Hu}$, C. 2018 [9] & Cohort stud & China & 66 & 256 & $\begin{array}{l}2010.01- \\
2014.09\end{array}$ & $\begin{array}{l}\text { not } \\
\text { sure }\end{array}$ & $\begin{array}{l}\text { not } \\
\text { sure }\end{array}$ & I & 25 & 23 & $\begin{array}{l}18 \\
\text { gauge }\end{array}$ & $\begin{array}{l}\text { Surgery, } \\
\text { chemotherapy }\end{array}$ \\
\hline Ahn, S. Y. 2019 [8] & Cohort stud & Korea & 540 & 270 & $\begin{array}{l}2004.01- \\
2010.12\end{array}$ & 63.7 & 64.1 & I & 26 & 20 & $\begin{array}{l}17-22 \\
\text { gauge }\end{array}$ & Surgery \\
\hline
\end{tabular}


Table 3 Relationship between PTNB and total recurrence rate

\begin{tabular}{|c|c|c|c|c|c|c|}
\hline \multirow[t]{2}{*}{ Research object } & \multicolumn{2}{|l|}{ PTNB } & \multicolumn{2}{|l|}{ NPTNB } & \multirow[t]{2}{*}{ weight $\%$} & \multirow[t]{2}{*}{$\mathrm{RR}(95 \% \mathrm{Cl})$} \\
\hline & events & non-events & events & non-events & & \\
\hline Matsuguma, H. 2005 [3] & 17 & 49 & 51 & 173 & 14.37 & $1.131(0.703,1.820)$ \\
\hline Inoue, M. 2011 [2] & 13 & 118 & 38 & 278 & 11.57 & $0.825(0.455,1.498)$ \\
\hline Asakura, K. 2012 [11] & 11 & 113 & 35 & 162 & 10.71 & $0.499(0.264,0.946)$ \\
\hline Kashiwabara, K. 2016 [12] & 14 & 49 & 23 & 63 & 11.92 & $0.831(0.465,1.483)$ \\
\hline Moon, S.M. 2017 [7] & 58 & 185 & 25 & 124 & 15.77 & $1.423(0.933,2.170)$ \\
\hline $\mathrm{Hu}, \mathrm{C.} 2018$ [9] & 21 & 45 & 78 & 178 & 16.42 & $1.044(0.701,1.556)$ \\
\hline Ahn, S. Y. 2019 [8] & 145 & 395 & 45 & 225 & 19.24 & $1.611(1.193,2.177)$ \\
\hline Total & 279 & 1003 & 295 & 1203 & 100 & $1.055(0.799,1.392)$ \\
\hline
\end{tabular}

using a random effects model. In patients without subpleural lesions, the total relative risk ratio (RR) was 1.827 (95\% confidence interval, 0.339-9.872; $p=0.483$; Fig. 5). The results show that in stage I lung cancers, PTNB will not increase the risk of pleural recurrence in patients without sub-pleural lesions.

\section{The analysis of sensitivity}

For each analysis, the statistics are merged after each study is removed in turn, and the results do not change statistically, indicating that the research results are reliable (Fig. 6).

\section{Publication bias}

The number of articles included is less 10 , so no publication bias test was performed.

\section{Discussion}

Tumors with different sizes and stages have different malignancy degree, so we limited the study to patients with stage I lung cancer. The main purpose of PTNB is to accurately identify the nodule's quality for surgical resection, and to avoid unnecessary surgical treatment to patients with benign nodules. In recent years, PTNB has developed into one of the most commonly used diagnostic methods for diagnosis of lung lesions, especially for peripheral lung cancer. Although its diagnostic accuracy is high and there are few recent complications, it is still inevitable to destroy the lung structure during the process. Therefore, the puncture may spread tumor cells to the airways, blood vessels, pleural cavity, chest wall and so on, increasing the rate of lung cancer metastasis in potentially curable cancer, so it is still necessary to find the occurrence rate of long-term complications

\begin{tabular}{|c|c|c|c|c|c|c|c|}
\hline Study & $R R$ & [95: Conf: & Interval] & \& welght & Study & \multirow{3}{*}{ AR (ass Cl) } & \multirow{3}{*}{ Weight } \\
\hline \multicolumn{5}{|c|}{ gen } & \multirow[t]{2}{*}{10} & & \\
\hline Matsuguna, H.2005 & 1.131 & 0.793 & 1.820 & 14.37 & & & \\
\hline Inoue, R. 2011 & 0.825 & 0.455 & 1.498 & 11.57 & & \multirow[b]{2}{*}{$1.13(0.70 .1 .1 .80)$} & \multirow{2}{*}{14.37} \\
\hline Asakura, X.2012 & 0.499 & 0.264 & 8.945 & 18.71 & Matsuguma, $\mathrm{H} .2006$ & & \\
\hline Kashinabara, R.2016 & 0.831 & 0.455 & 1.483 & 11.92 & \multirow{2}{*}{ Inoue, M 2011 } & \multirow{2}{*}{$0.83(2.45,1.50)$} & \multirow{2}{*}{11.57} \\
\hline Moon, 5.1 .2817 & 1.423 & 0.993 & 2.170 & 15.77 & & & \\
\hline $\mathrm{Hu}, \mathrm{C.2018}$ & 1.044 & 0.791 & 1.556 & 16.42 & Asakura,K2012 & \multirow[t]{2}{*}{$0.50(0.26 .0 .055)$} & 10,71 \\
\hline Ahn, 5. Y.2019 & 1.611 & 1. 193 & 2.177 & 19.24 & \multirow{2}{*}{ Kashiwabara, K2016 } & & \multirow{2}{*}{11.92} \\
\hline (n).................. & & & & 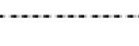 & & $Q B ., 0.47,1.48)$ & \\
\hline -... & & & & & Moon, S.M.2017 & \multirow[t]{2}{*}{$1.4(0,90.217)$} & \multirow[t]{2}{*}{15.77} \\
\hline \multicolumn{6}{|c|}{. Hu, 2018} & & \\
\hline \multicolumn{5}{|c|}{ (n) } & Ana, \$, Y.2019 & $1.61(1.19 .218)$ & 19.24 \\
\hline \multirow{3}{*}{\multicolumn{5}{|c|}{$\begin{array}{l}\text { Heterogeneity chi-squared }=14.97 \text { (d.f. }-6 \text { ) p }=0.021 \\
\text { I-squared (variation in } 8 \mathrm{~g} \text { attributable to heterogeneity) }=59.9 \% \\
\text { Estinate of between-study variance Tau-squared }=0.0605\end{array}$}} & Overall (1-squared $=59,9 \%, p=0.02$ & \multirow[t]{3}{*}{$1.05(0.00,139)$} & \multirow[t]{3}{*}{100,00} \\
\hline & & & & & & & \\
\hline & & & & & NOTE: Weights ar trom randem efocts andiys & & \\
\hline \multicolumn{5}{|c|}{ Test of $R=1: z=0.38 p=0.705$} & 264 & \multicolumn{2}{|l|}{379} \\
\hline \multicolumn{8}{|c|}{$\begin{array}{l}\text { Fig. } 2 \text { Relationships between PTNB and total recurrence rate. Legends: Significant heterogeneity was found in the study }\left(I^{2}=59.9 \%, p=0.021\right) \text {. } \\
\text { The total relative risk ratio (RR) was } 1.055(95 \% \mathrm{Cl}, 0.799-1.392 ; p=0.705 ; \text { Fig. } 2)\end{array}$} \\
\hline
\end{tabular}


Table 4 Relationship between PTNB and pleural recurrence rate

\begin{tabular}{|c|c|c|c|c|c|c|}
\hline \multirow[t]{2}{*}{ Research object } & \multicolumn{2}{|l|}{ PTNB } & \multicolumn{2}{|l|}{ NPTNB } & \multirow[t]{2}{*}{ weight $\%$} & \multirow[t]{2}{*}{$\operatorname{RR}(95 \% \mathrm{Cl})$} \\
\hline & events & non-events & events & non-events & & \\
\hline Matsuguma, H. 2005 [3] & 6 & 60 & 2 & 222 & 12.14 & $10.182(2.104,49.264)$ \\
\hline Inoue, M. 2011 [2] & 8 & 123 & 5 & 315 & 16.65 & $3.908(1.303,11.726)$ \\
\hline Asakura, K. 2012 [11] & 1 & 123 & 7 & 190 & 8.71 & $0.227(0.028,1.823)$ \\
\hline Flechsig.P. 2015 [10] & 1 & 25 & 2 & 7 & 7.71 & $0.173(0.018,1.688)$ \\
\hline Kashiwabara, K. 2016 [12] & 7 & 56 & 5 & 81 & 16.63 & $1.911(0.636,5.745)$ \\
\hline Moon, S.M. 2017 [7] & 23 & 223 & 3 & 146 & 15.74 & $4.644(1.419,15.200)$ \\
\hline Ahn, S. Y. 2019 [8] & 54 & 486 & 14 & 256 & 22.41 & $1.929(1.091,3.408)$ \\
\hline Total & 100 & 1096 & 38 & 1217 & 100 & $2.098(0.985,4.469)$ \\
\hline
\end{tabular}

such as pleural recurrence. Since PTNB was first reported in 1965, some typical cases of pleural recurrence and needle channel implantation have been confirmed [1]. However, it was not until 2005 that Matsuguma and others conducted a cohort study and found that PTNB increased pleural recurrence in patients with stage I lung cancer [3]. After several studies conducted later, it was found that PTNB did not significantly increase the total recurrence rate of lung cancer. So it has not been agreed whether PTNB will increase the recurrence of pleura $[2$, 3, 7-12].

The results of this study did not find a significant correlation between PTNB and the total recurrence rate and pleural recurrence rate, indicating that the cancer recurrence rate is mainly related to the malignant degree of the primary tumor whereas not to the tissue destruction and tumor cells caused by lung cancer puncture. The tumor cells were separated from the original growth environment, so the probability of colonization and metastasis decreased in a new environment. In the included studies, most of the tumors in the PTNB group were larger than those in the NPTNB group and larger tumors were more likely to be accompanied by adverse results, so during comparison, they may mask the effect of PTNB on pleural metastasis and led to more false negative results. Therefore, there may be no significant correlation between PTNB and the recurrence rate, which should be further studied by improving tumor size homogeneity and eliminating related interference. But there are not enough typical samples at present.

It is worth noticing that compared with patients without sub-pleural lesions, PTNB increases the risk of

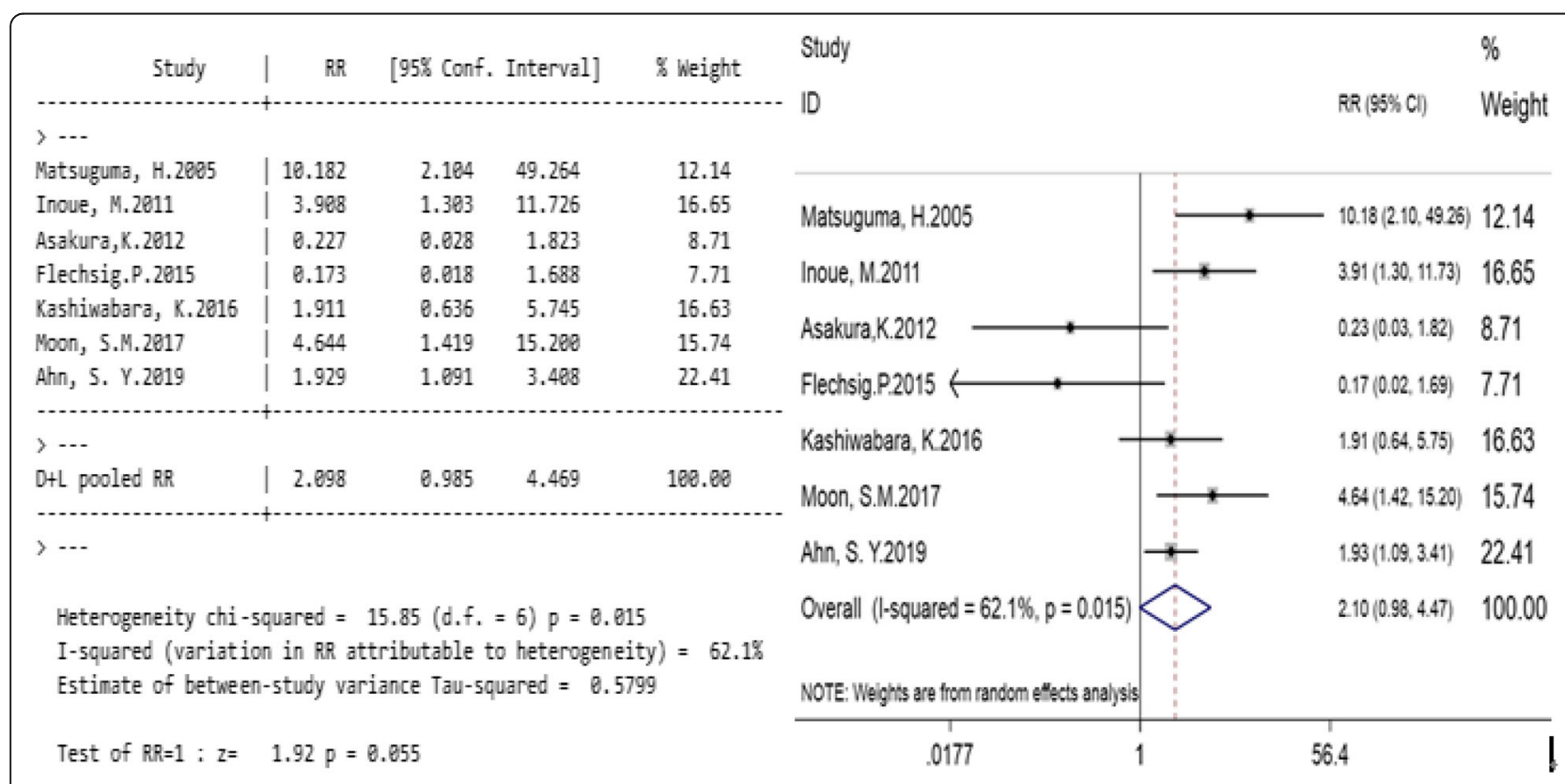

Fig. 3 Relationships between PTNB and pleural recurrence rate. Legends: Significant heterogeneity was found in the study $\left(I^{2}=62.1 \%, p=0.015\right.$; Fig. 3). The total relative risk ratio (RR) was 2.098 ( $95 \%$ Cl, 0.985-4.469; $p=0.055$; Fig. 3) 
Table 5 Relationship between PTNB and the pleural recurrence rate of the patients with sub-pleural lesions

\begin{tabular}{|c|c|c|c|c|c|c|}
\hline \multirow[t]{2}{*}{ Research object } & \multicolumn{2}{|l|}{ PTNB } & \multicolumn{2}{|l|}{ NPTNB } & \multirow[t]{2}{*}{ Weight\% } & \multirow[t]{2}{*}{$\mathrm{RR}(95 \% \mathrm{Cl})$} \\
\hline & events & non-events & events & non-events & & \\
\hline Inoue, M. 2011 [2] & 8 & 44 & 2 & 129 & 24.2 & $10.077(2.213,45.882$ \\
\hline Kashiwabara, K. 2016 [12] & 4 & 12 & 1 & 27 & 15.49 & $7.000(0.854,57.361)$ \\
\hline Moon, S.M. 2017 [7] & 11 & 86 & 2 & 38 & 60.31 & $2.268(0.526,9.775)$ \\
\hline Total & 23 & 142 & 5 & 194 & 100 & $4.891(2.012,11.891)$ \\
\hline
\end{tabular}

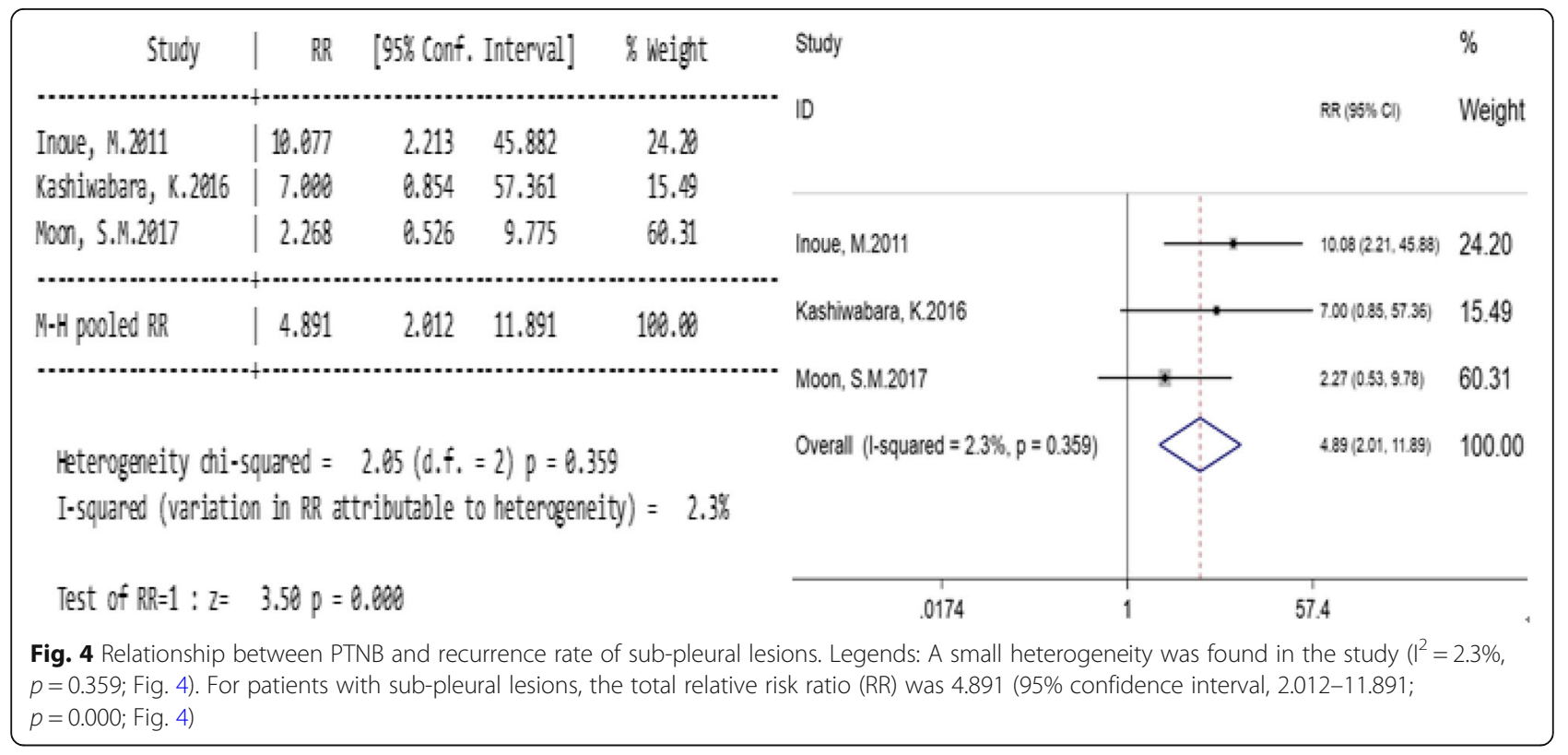

Table 6 Relationship between PTNB and the pleural recurrence rate of the patients without sub-pleural lesions

\begin{tabular}{|c|c|c|c|c|c|c|}
\hline \multirow[t]{2}{*}{ Research object } & \multicolumn{2}{|l|}{ PTNB } & \multicolumn{2}{|l|}{ NPTNB } & \multirow[t]{2}{*}{ Weight\% } & \multirow[t]{2}{*}{$\mathrm{RR}(95 \% \mathrm{Cl})$} \\
\hline & events & non-events & events & non-events & & \\
\hline Inoue, M. 2011 [2] & 0 & 79 & 3 & 182 & 21.75 & $0.332(0.017,6.356)$ \\
\hline Kashiwabara, K. 2016 [12] & 3 & 23 & 4 & 40 & 44.65 & $1.269(0.308,5.231)$ \\
\hline Moon, S.M. 2017 [7] & 12 & 134 & 1 & 108 & 33.6 & $8.959(1.183,67.864)$ \\
\hline 总计 & 15 & 236 & 8 & 330 & 100 & $1.829(0.339,9.872)$ \\
\hline
\end{tabular}




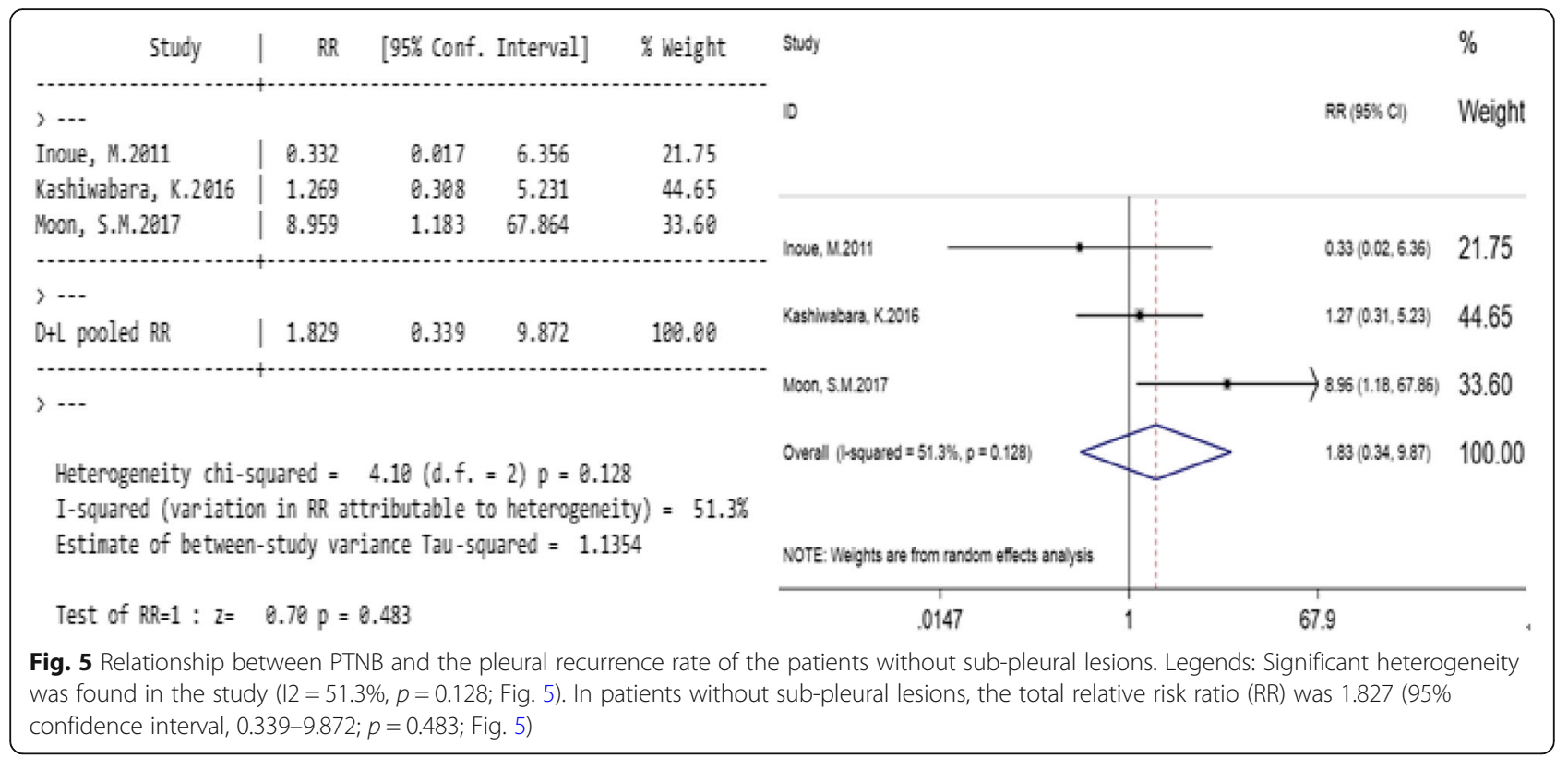

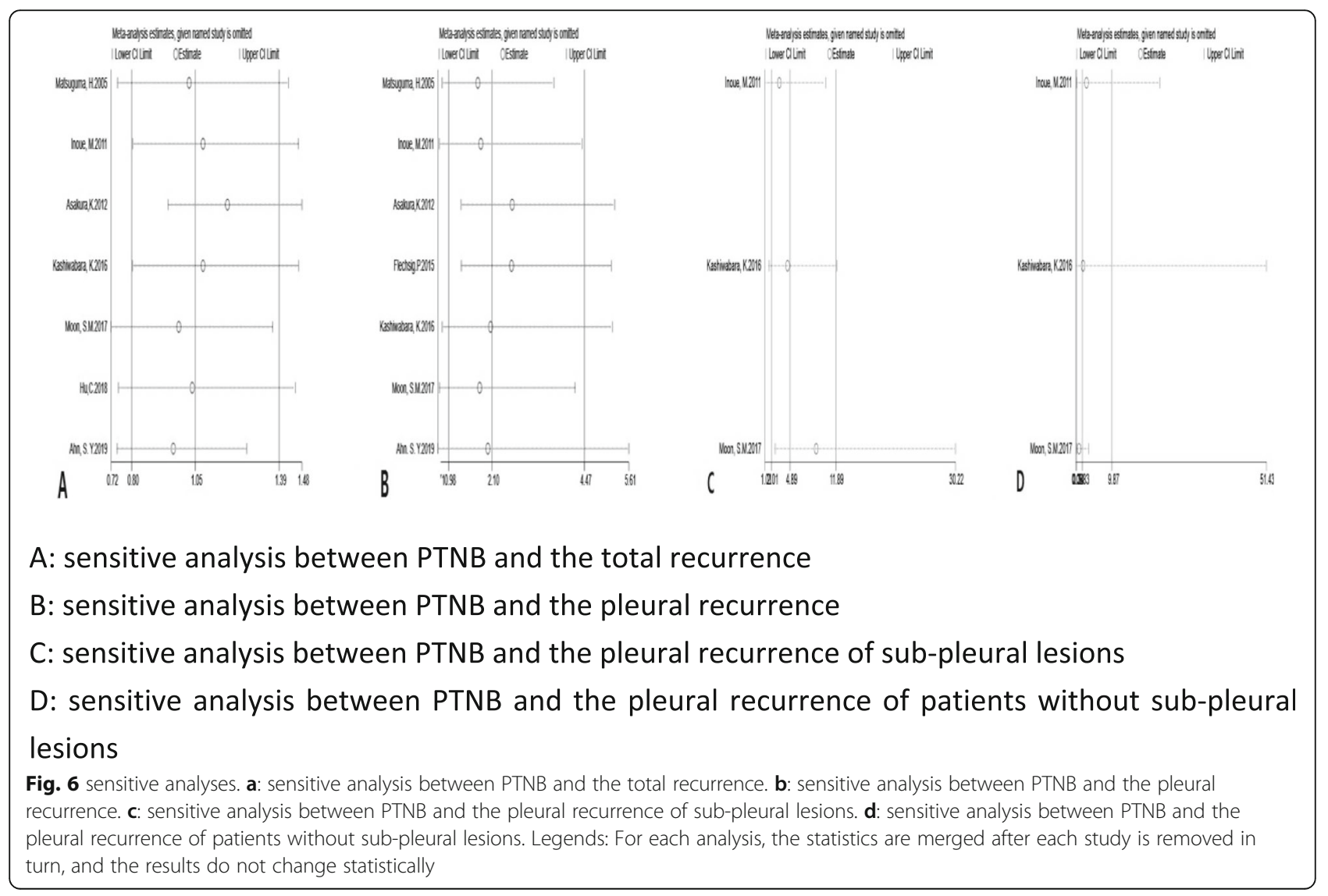


pleural recurrence in stage I lung cancer patients with sub-pleural lesions. Because the location of the lesion is close to the pleura, some tumors are more likely to be accompanied by microscopic lymphoid infiltration, visceral pleural microinfiltration or pleural contact. These greatly increase the risk of pleural recurrence $[7,8]$, while the presence of visceral pleural invasion is not fully studied in their analysis. In the PTNB group, the pleural recurrence rate in patients with sub-pleural lesions (from 11 to $25 \%$ ) was significantly higher than that in patients without sub-pleural lesions (from 0 to $12 \%$ ). (Tables 5 and 6) While in the non-PTNB group, the pleural recurrence rate in the sub-pleural lesion group $(2-5 \%)$ was similar to that in patients without sub-pleural lesion group (1-9\%). (Tables 5 and 6).

Limitations: the main limitation is that the number of documents available is small and the sample size is insufficient. In addition, the included studies can not well balance the effects of many other confounding factors, such as tumor size, pathological differentiation and fibrosis state, puncture depth and times during the puncture, choice of puncture needle, intraoperative surgical methods, intraoperative use of chemotherapeutic drugs, postoperative follow-up time, postoperative adjuvant therapy and so on.

\section{Conclusions}

To sum up, current evidence suggests that PTNB is not associated with an increase in the total recurrence rate and pleural recurrence rate in patients with stage I lung cancer. However, for patients with early sub-pleural lesions, PTNB will increase the risk of pleural recurrence, so it is still necessary to choose PTNB carefully. Because of the limitations of this study, large-scale, prospective and multicenter studies are still needed.

\section{Supplementary information}

Supplementary information accompanies this paper at https://doi.org/10. 1186/s12890-020-01235-2.

\section{Additional file 1.}

\section{Abbreviations}

PTNB: Percutaneous transthoracic needle biopsy; PRISMA: Preferred reporting items for systematic review and meta-analysis; SCLC: Small cell lung cancer; NSCLS: Non-small cell lung cancer; RR: Relative risk

\section{Acknowledgements}

The authors thank all people who responded to our screening and analysis.

\section{Authors' contributions}

$\mathrm{HCL}$ was majored in the study design, literature search, review of the articles, extraction of the data, statistical analysis and was the major author of writing the manuscript. RC contributed to the study design, literature search, review of the articles and revision of the manuscript. JZ revised the manuscript. All authors read and approved the final manuscript.

\section{Funding}

1. Natural Science Foundation of Shandong Province No.ZR2018MH025
2. Primary Research \& Developement Plan of Shandong Province No. 2019GSF108076

Availability of data and materials

The data supporting our findings can be found by contacting us (zhaojianjn@sdu.edu.cn).

\section{Ethics approval and consent to participate}

These were waived as this study was only based on the summary results of previously published articles and individual patient data was not obtained or accessed.

\section{Consent for publication}

Not applicable.

\section{Competing interests}

The authors declare that they have no competing interests.

Received: 23 May 2020 Accepted: 14 July 2020

Published online: 20 July 2020

References

1. Huang $L$, Tsai $C$. Chest wall implantation of lung cancer following percutaneous transthoracic biopsy. Postgrad Med J. 2019. https://doi.org/10. 1136/postgradmedj-2018-136288

2. Inoue $M$, Honda O, Tomiyama N, Minami M, Sawabata N, Kadota Y, et al. Risk of pleural recurrence after computed tomographic-guided percutaneous needle biopsy in stage I lung cancer patients. Ann Thorac Surg. 2011. https://doi.org/10.1016/j.athoracsur.2010.12.032.

3. Matsuguma H, Nakahara R, Kondo T, Kamiyama Y, Mori K, Yokoi K. Risk of pleural recurrence after needle biopsy in patients with resected early stage lung cancer. Ann Thorac Surg. 2005. https://doi.org/10.1016/j.athoracsur. 2005.06.074

4. Kozuka H, Taniguchi Y, Fukumoto K, Matsui H, Saito T, Murakawa T. Is there any oncological concern about preoperative biopsy for Resectable lung Cancer patients? J Thorac Oncol. 2017;122(11):S2190-1.

5. Kim JH, Kim YT, Lim HK, Kim YH, Sung SW. Management for chest wall implantation of non-small cell lung cancer after fine-needle aspiration biopsy. Eur J Cardiothorac Surg. 2003. https://doi.org/10.1016/s10107940(03)00095-2.

6. Guo Z, Shi H, Li W, Lin D, Wang C, Liu C, et al. Chinese multidisciplinary expert consensus: guidelines on percutaneous transthoracic needle biopsy. Thorac Cancer. 2018. https://doi.org/10.1111/1759-7714.12849 Epub 2018 Sep 17.

7. Moon SM, Lee DG, Hwang NY, Ahn S, Lee H, Jeong BH, et al. Ipsilateral pleural recurrence after diagnostic transthoracic needle biopsy in pathological stage I lung cancer patients who underwent curative resection. Lung Cancer. 2017. https://doi.org/10.1016/j.lungcan.2017.07.008.

8. Ahn SY, Yoon SH, Yang BR, Kim YT, Park CM, Goo JM. Risk of pleural recurrence after percutaneous transthoracic needle biopsy in stage I non-small-cell lung cancer. Eur Radiol. 2019. https://doi.org/10.1007/s00330-018-5561-5.

9. Hu C, Jiang J, Li Y, Zhang C, Zhang W, Jiang H, et al. Recurrence risk after preoperative biopsy in patients with resected early-stage non-small-cell lung cancer: a retrospective study. Cancer Manag Res. 2018. https://doi.org/ 10.2147/CMAR.S166930.

10. Flechsig P, Kunz J, Heussel CP, Bozorgmehr F, Schnabel P, Dienemann $H_{4}$ et al. Invasive lung cancer staging: influence of CT-guided core needle biopsy on onset of pleural carcinomatosis. Clin Imaging. 2015. https://doi. org/10.1016/j.clinimag.2014.10.005.

11. Asakura K, Izumi Y, Yamauchi $Y$, Nakatsuka S, Inoue $M$, Yashiro $H$, et al. Incidence of pleural recurrence after computed tomography-guided needle biopsy in stage I lung cancer. PLoS One. 2012. https://doi.org/10.1371/ journal.pone.0042043.

12. Kashiwabara K, Semba H, Fujii S, Tsumura S. Preoperative percutaneous transthoracic needle biopsy increased the risk of pleural recurrence in pathological stage I lung Cancer patients with sub-pleural pure solid nodules. Cancer Investig. 2016. https://doi.org/10.1080/07357907.2016.1212061.

\section{Publisher's Note}

Springer Nature remains neutral with regard to jurisdictional claims in published maps and institutional affiliations. 